\title{
Proyectos críticos y pensamiento histórico en Pedro Henríquez Ureña, Alfonso Reyes y José Carlos Mariátegui*
}

Critical Projects and Historical Thinking in Pedro Henríquez Ureña, Alfonso Reyes and José Carlos Mariátegui's Essays

\author{
Clara María Parra Triana \\ Universidad de Concepción \\ cparratriana@hotmail.com
}

Analizo las obras críticas de Pedro Henríquez Ureña, Alfonso Reyes y José Carlos Mariátegui en las que se advierte la búsqueda de métodos idóneos para el estudio de la literatura con relación a la vida social. Nuestros pensadores consideran la producción literaria hispanoamericana como un corpus heterogéneo que es preciso leer en relación con los procesos históricos y culturales que la engendran y en los que participa activamente. El pensamiento histórico y crítico es la clave para hacer de los estudios literarios hispanoamericanos un discurso legítimo de modernidad intelectual.

Palabras clave: crítica literaria, pensamiento histórico, autonomía intelectual.

I analize Pedro Henríquez Ureña, Alfonso Reyes and José Carlos Mariátegui's criticism works in which it can be found the search for the accurated methods for literature studing in its relation to social life. Our intellectuals consider Spanish american literary production as a heterogeneous corpus that must be read linked to the cultural and historical processes that breed it and that it participates in. Historical and critical thought is the key to make Literary Studies an authentic manifestation of modern intelligentsia.

Keywords: literary criticism, historical thought, intellectual autonomy.

Recibido: 18 de marzo de 2011

Aprobado: 2 de mayo de 2011

\footnotetext{
* Esta reflexión hace parte de mi tesis para optar al grado de Doctor en Literatura Latinoamericana de la Universidad de Concepción, titulada: "'La pugna secreta': consolidación del campo de los estudios literarios hispanoamericanos en los ensayos de Pedro Henríquez Ureña, Alfonso Reyes y José Carlos Mariátegui", apoyada por la beca MECESUP.
} 
Pedro Henríquez Ureña, Alfonso Reyes y José Carlos Mariátegui investigaron sobre las formas de lograr una visión cabal de la producción literaria hispanoamericana, que privilegiara siempre "el contacto directo con las obras" (cf. Reyes), lo que al mismo tiempo exigía no perderse en la superabundancia de la producción literaria. Esto último causó la implementación de prácticas marcadas por un criterio selectivo de lo que ellos denominaron "autores y obras fundamentales". Este fue sin duda un gesto de subversión, pues ya no se trataba de demostrar cuán prolíficos y versados eran los escritores hispanoamericanos, sino de ver hasta dónde la escritura lograba ser expresión constructora y crítica. Tanto Henríquez Ureña como Reyes y Mariátegui asumen una posición crítica ante el deseo de definir los principios de lectura de la tradición literaria en Hispanoamérica. Cada uno de ellos realiza propuestas y ejercicios de lectura que a su vez se convierten en manifestaciones del pensamiento autónomo que ellos advierten como necesidad.

Reyes destaca el papel que desempeña la elaboración de manuales y antologías en la formación de pautas de lectura. En su conferencia "Valor de la literatura hispanoamericana" [1941], señala:

Por suerte toda literatura admite ser estudiada en torno a unos cuantos nombres eminentes, los cuales sirven de puntos de concentración o puntos de arranque a las cohortes, las generaciones, las pléyades [...] (Reyes $\mathrm{La}$ experiencia... 126).

Tiene sus clásicos América, y ellos debieran estar en la memoria de todos. Pero en las recopilaciones particulares andan confundidos muchos otros que no lo son, aun cuando puedan poseer indiscutible valor casero. [...] Al mundo no debemos mostrar canteras y sillares, sino a ser posible, edificios ya construidos.

El fárrago, el fárrago es el que nos mata (ibid. 128 [El énfasis es mío]).

La voluntad de autodefinición y autorrepresentación del pensamiento es legible en el fragmento anterior. Sin lugar a dudas la preocupación del pensador mexicano apunta a la elaboración urgente de guías que completen el circuito de la producción artística hispanoamericana. La existencia de escritores clásicos precisa de lectores que completen su trayecto (que los hagan ser clásicos vivos); el ejercicio crítico que le corresponde a la recepción de las obras pule el fárrago, permite apreciar la relevancia y aporte de las obras, y ante todo constituye la "moneda cultural" de la América hispana para el resto del mundo.

Pero el proyecto planteado por Reyes -que es, como veremos más adelante, coherente y dialogante con los proyectos de historia literaria de Henríquez Ureña y Mariátegui- no se resuelve de una manera simple, en este apreciamos dos cuestionamientos fundamentales en la definición del pensamiento crítico e histórico que nos ocupa: ¿con qué criterio se han de realizar las selecciones de un corpus tan heterogéneo y plural como el de nuestra América? y ¿de 
qué manera es posible definir lo que ha de ser leído, si nuestro interés es que se conozca y comprenda nuestro espíritu hispanoamericano?

Henríquez Ureña había señalado en "Caminos de nuestra historia literaria" de 1928, la apremiante disolución de pseudoproblemas como el de la exuberancia, el supuesto andalucismo, la dicotomía de la América buena y la mala, los nacionalismos disimuladores, entre otros, para pasar por fin al enfrentamiento de discusiones presentes en las obras para su respectiva interpretación y selección. Este texto (anterior a la conferencia de Reyes) ya reclamaba la capacidad de definición y elaboración de aquellos "edificios ya construidos" tanto de la producción literaria como de la recepción crítica:

Hace falta poner en circulación tablas de valores: nombres centrales y libros de lectura indispensables.

\section{$[\ldots]$}

La historia literaria de la América española debe escribirse alrededor de unos cuantos nombres centrales: Bello, Sarmiento, Montalvo, Martí, Darío y Rodó (Obra crítica 255).

Los caminos de la historia literaria indicados por Henríquez Ureña denuncian la carencia de herramientas críticas a la que se enfrentan los lectores de nuestra literatura. Se observa la desazón por la falta de emprendimiento para llevar a cabo ejercicios de síntesis crítica, en donde se encuentren las producciones más relevantes y la literatura se aprecie en su verdadera dimensión sociocultural.

La síntesis crítica a la que aludo consiste en el llamado que realizan nuestros intelectuales al conocimiento mediante la integración de nuestras realidades y producciones culturales, y a su respectiva puesta a prueba mediante la relectura analítica y la reinvención de nuestros componentes culturales, a partir de un acercamiento propio a estos, sin intermediarios. Este "ensayo de síntesis" que la América hispana está llamada a intentar (cf. Reyes), que además edificaría un futuro de mayor conciencia histórica (cf. Henríquez Ureña), solo es posible si construimos nuestras propias herramientas para comprendernos ${ }^{1}$.

Lo que les preocupa a nuestros pensadores es la manera como se lee y como se interpreta la producción literaria. Ellos ya no se plantean la pregunta sobre la existencia del corpus, sino sobre la forma de abordarlo sin vaciarlo. Para Henríquez Ureña, Reyes y Mariátegui el pensamiento histórico se constituye en la clave del recorrido interpretativo del crítico formado con gran disposición hacia la lectura. Entonces, las historias literarias las conciben no tanto como repertorios enumerativos de la cantidad de obras escritas en

\footnotetext{
1 Sobre este ensayo de síntesis crítica trabajó también Mariano Picón-Salas con el ejercicio interpretativo de la formación del alma criolla en su obra mayor De la conquista a la independencia [1944]. El pensador venezolano formó parte activa de la comunidad discursiva que se propuso superar los prejuicios nacionalistas, tratando de ver en profundidad los legados espirituales que hacen del hombre hispanoamericano un sujeto complejo.
} 
una determinada tradición literaria, sino como selecciones interpretativas de la calidad de las obras presentes en dicha tradición.

Este planteamiento no contempla un criterio elitista, como algunos críticos han deseado leer en nuestros pensadores. Ellos configuraron un proyecto subversivo: el de derribar la visión romántica que invadía a la crítica de aquel entonces, cuyas convicciones hacían creer que la literatura hispanoamericana tenía su valor en la exuberancia, de allí la consigna del dominicano: "no llegaremos nunca a trazar el plano de nuestras letras si no hacemos previo desmonte" (Obra crítica 258). Aquel "desmonte previo" al que se refiere Henríquez Ureña se convierte en su imperativo fundamental: la búsqueda de nuestra expresión. El desmonte es la interpretación, el diálogo fluido, lejano a las pseudocategorías que limitan el objeto estético a la mera afirmación de identidades o al encasillamiento basado en escuelas, movimientos o generaciones que nada tienen que ver con las orientaciones artísticas y críticas. Reyes:

En el mismo sentido del "desmonte previo" de Henríquez Ureña, indicaba

Yo no recomendaría en los seminarios y gimnasios otro ejercicio que no sea el de despojar la tradición.

Pues no todo lo que ha existido debe conservarse, por la sencilla razón de que como todo tiene sus efectos hay masas enteras de hechos y actividades que han quedado del todo resumidas, vaciadas, aprovechadas en un resultado compendioso. Este resultado viene a ser entonces lo único que establece tradición; es decir, lo que crea una porción viva a lo largo del ser histórico que somos.

\section{$[\ldots]$}

Hay que jardinar esta maleza (La experiencia... 129 [El énfasis es mío]).

El despojo de la tradición no implica su destrozo ni su aniquilación; es la revisión y capacidad de selección crítica de los lectores y estudiosos lo que contribuye a reavivar los anaqueles. El crítico es el encargado de enriquecer el circuito vivo de esta tradición. Nuestros pensadores desconocen otra forma de dar vida a la tradición literaria que no sea la de la lectura directa de las obras y la discriminación sustentada en la visión de nuestra existencia histórica.

El pensamiento histórico en los estudios literarios es considerado por nuestros pensadores como la herramienta más clarificadora para comprender los movimientos culturales dentro de la vida social ${ }^{2}$. Reyes propone en

2 En "Historia de la historiografía y de la crítica literarias latinoamericanas. Historia de la conciencia histórica" (1986), Carlos Rincón sostiene que la literatura, si bien posee un camino propio en la historia, también se involucra en su construcción, por lo que su estudio a manera de "síntesis interpretativa" no ha podido soslayar la vida social y su elaboración de significados. Es de notable relevancia que para el año 86 aún prevalezca en la historiografía literaria la 
"El método histórico en la crítica literaria" [1941] que este método es un complemento de la actividad crítica, pues le da profundidad, rigor y visión de conjunto al estudio del fenómeno literario, siempre y cuando el método no devore la instancia crítica y no se pierda en el cientificismo del dato y la enumeración. La historia literaria, señala Reyes, se consolida como la posibilidad de apreciar la literatura dentro de un conjunto dialogante, como una senda transitable de expresiones. Para comprender estas sendas o caminos de la marcha literaria, el crítico ha de implementar categorías de interpretación que sean coherentes con el recorrido que la literatura señala, pues cada tradición literaria existente en el panorama mundial posee un trayecto propio que el crítico ha de clarificar.

Henríquez Ureña y Mariátegui abordan estas problemáticas desde sus ejercicios de historia literaria. El pensamiento dialéctico guía sus propuestas siempre a partir de un deseo de comprender la totalidad, o por lo menos, el germen de la expresión literaria hispanoamericana, adoptando criterios menos puristas y clasificatorios en comparación con los que los habían precedido para implementar reflexiones de carácter histórico cultural de la obra literaria. Este pensamiento dialéctico, que críticos como Gutiérrez Girardot y Sarlo han referido, se puede observar en sus ideas sobre la interpretación de lo nacional en los marcos de lo hispanoamericano y lo universal, y la retroalimentación entre la producción cultural y la vida social: "La literatura ocupa una relación variable en la serie cultural y la serie cultural tiene una relación también variable en el resto de los niveles sociales. Pensar la literatura supone, entonces, pensar no solo relaciones sino también diferencias históricas y de formación social" (Sarlo, "Pedro Henríquez Ureña..." 882).

Los trabajos de historia literaria que realizan Mariátegui en "El proceso de la literatura" [1928], y Henríquez Ureña en Seis ensayos en busca de nuestra expresión [1928] y Las corrientes literarias en la América hispánica [1946] conservan el germen problemático de la adopción del pensamiento dialéctico para los estudios de la literatura hispanoamericana. La relación que establecen nuestros pensadores desde el punto de vista histórico entre la producción literaria y la vida social y cultural, no es determinista. Ellos observan que las "formas de expresión literarias" hacen parte de un entramado complejo conformado por posicionamientos ideológicos de los actores culturales, aspiraciones estéticas y posibilidades socioeconómicas de la producción literaria. Ellos reconocen también que para comprender el fenómeno literario en su totalidad -o por lo menos en su aspiración de totalidad-, se debe incluir en la discusión la recepción crítica que han experimentado dichos objetos. Para llegar a la interpretación de las obras el crítico ha de pronunciarse a partir de un frente doble: el del lector de literatura y el del lector de la crítica.

La compleja red de relaciones que se establece entre la literatura y la sociedad es el fundamento de la crítica e historia literaria de José Carlos Mariátegui; así nos lo demuestran muy acertadamente Guillermo Mariaca,

carencia de elementos para reconocer la significación de las literaturas heterogéneas en el conglomerado hispanoamericano. Veremos que los ejercicios de historia literaria realizados por Mariátegui y Henríquez Ureña ya declaraban estas problemáticas como asuntos centrales en la discusión literaria y social. 
Adalbert Dessau, Antonio Melis y Fernanda Beigel, por solo citar algunos de los más acuciosos lectores de la obra crítica del pensador peruano ${ }^{3}$. La relevancia de "El proceso de la literatura" para las letras hispanoamericanas es innegable, por cuanto en este, Mariátegui "procesa", es decir, juzga, señala y toma partido frente a la tradición crítica y literaria del Perú. En otras palabras, Mariátegui realiza el ejercicio indicado por Henríquez Ureña de "desmontar nuestras letras" (para el caso, las letras peruanas), dando una visión general de los procesos experimentados por las expresiones literarias peruanas a través del tiempo y de las visiones particulares de los escritores. Su trabajo de desmonte -que para mí es un sinónimo de dejar entrar el pensamiento histórico a la reflexión literaria- demuestra la insuficiencia de las viejas formas de ordenación del material literario, y mediante la adopción de un nuevo procedimiento, ensaya la interpretación de sus manifestaciones.

Para Mariátegui, "procesar" la literatura peruana es una forma de evaluar críticamente el tradicionalismo en el que se había instalado hasta el momento la crítica literaria entendida como "técnica". Su criterio parte de la adopción de un sistema -que es también su toma de posición-, para así realizar una selección de autores y obras que él considera fundamentales en el desarrollo literario del Perú.

Antes de entrar al corpus de autores y textos seleccionados, problematiza la clásica noción que ha guiado los trabajos de historia literaria tradicionales: la noción de "literatura nacional". La discusión del autor del "proceso" objeta la idea consabida de que la lengua es la portadora de la nacionalidad, o si se quiere, de la cacofónica idea de identidad. Su argumento más fuerte radica en que para llegar a considerar la "literatura peruana" como tal, no es posible exigirle que se despoje de la lengua española como mecanismo de expresión, pues la lengua española en el Perú, al igual que en otros países colonizados por España, posee un espíritu propio que lo hace particularizarse e identificarse con su realidad y experiencia de vida espiritual e ideológica. Asuntos como el dualismo irresuelto quechua-español, la americanización de la lengua española como primera manifestación de la literatura nacional -no en el sentido homogenizador del término sino en su carácter de expresión de autonomía-, "desmontan" el esquema tradicional decimonónico:

Nación $\longrightarrow$ Lengua Nacional $\longrightarrow$ Literatura Nacional ${ }^{4}$

\footnotetext{
3 La problemática del colonialismo cultural, cuyas discusiones con relación a la idea de nación y el papel del intelectual a nivel político, ideológico y social, es una de ellas, pues esta se hace legible a partir de una historia de la literatura. Mariaca sostiene que la idea del colonialismo cultural es el centro de la postura crítica mariateguiana, por lo que los debates del pensador peruano con relación al indigenismo, la vanguardia, la literatura popular y el bilingüismo se vinculan directamente a los complejos procesos surgidos a partir del fenómeno colonial. 4 Este fue el esquema sustentado por los defensores de la nacionalidad como identidad social durante el siglo XIX, en el auge de la consolidación de las naciones hispanoamericanas. José Victorino Lastarria preguntaba en el "Discurso inaugural de la sociedad literaria" de 1842: "¿A dónde hallaremos la expresión de nuestra sociedad, el espejo en el que se refleja nuestra nacionalidad?" (en Promis 83), su respuesta buscaba hacer de la lengua española la bandera de la nacionalidad (una bandera heredada, por supuesto), que había que defender de los peligrosos "empréstitos" o contaminaciones de otras lenguas como el francés. Lastarria considera que la lengua nacional es tanto más nacional cuanto más popular
} 
El desmonte que Mariátegui hace de este esquema radica en el origen absoluto que plantean los defensores de la lengua y el alma nacional a partir de las independencias políticas. Mariátegui fundamenta su postura a partir del cuestionamiento a la homogeneidad postulada por esa idea de literatura peruana apostillada a la literatura española. La expresión de la literatura peruana (ligada a la letra) sí es de raigambre española, pero su germen espiritual -su naturaleza-, que está por definirse, ha de buscarse en lo eminentemente peruano, es decir, en la formación de su propia expresión que no tiene nada de exuberante, sino que su pertenencia se observará en la capacidad para abordar reflexivamente las particulares concepciones del mundo y de la historia que la literatura arroja.

En este sentido, Mariátegui rediseña los procedimientos convencionales de "explicación y ordenación" que han intentado dar cuenta de nuestras literaturas $y$, con relación a su posicionamiento estético, pero también respondiendo a un criterio histórico-social, implementa un acercamiento no linealmente histórico, ni prosaicamente sociológico, formulando la toma de posición de la obra y/o del autor respecto de la realidad y al entorno cultural.

Lo que Mariátegui denomina "período" (no necesariamente en el sentido cronológico) dentro de sus criterios de interpretación de la tradición literaria peruana, alude tanto a la forma de vida y de desarrollo de las sociedades como a los tipos de elaboración y reflexión que cada sociedad realiza sobre sí misma. De esta manera, el periodo colonial refiere a los usos y costumbres de la sociedad peruana y también a la actitud de dependencia (copia, traslado) que asumen sus exponentes ante la elaboración de temas y el posicionamiento ante los problemas expresivos y humanos.

La noción de cosmopolitismo, de las categorías mariateguianas, se entiende como la actitud de apertura hacia otras fuentes de cultura, para ser más precisos, es la construcción del puente que conecta a América directamente con Occidente. Este periodo, hace las veces de momento de transición entre la presencia colonial y la acción mediante la adquisición de conciencia histórica de los pueblos hispanoamericanos. Lo llamativo de la noción de cosmopolitismo explicada por Mariátegui es su capacidad para hacer visible lo propio y establecerlo como categoría de explicación de la producción literaria; tal es el caso de la idea de lo popular como germen de vida de la cultura y de la lengua.

El período cosmopolita, que para Mariátegui ha de ser una actitud constante, tanto de los pueblos como de sus intelectuales orgánicos, en el deseo de crecimiento y autoconstrucción continuos, contribuye a la construcción de la conciencia criolla, la cual tiene a cargo la expresión de la nacionalidad, desde la perspectiva de Mariátegui:

es, lo cual no está muy lejos de lo expuesto por Henríquez Ureña, Reyes y Mariátegui con relación a la "vida real de la literatura" que se halla en las expresiones orales y populares. Lo que no incluye el esquema de Lastarria es la explosión crítica que el lenguaje literario como problema de expresión alberga. Lastarria y sus contertulios defienden el papel del idioma en la configuración de las nuevas nacionalidades, mientras que nuestros pensadores consideran ampliar las discusiones sobre la lengua hacia una más abarcadora que contemple las problemáticas del lenguaje. 
El criollo peruano no ha acabado aun de emanciparse espiritualmente de España. Su europeización -a través de la cual debe encontrar por reacción, su personalidadno se ha cumplido sino en parte. Una vez europeizado el criollo de hoy no puede dejar de ver el drama del Perú. Es él precisamente el que, reconociéndose a sí mismo como un español bastardeado siente que el indio debe ser el cimiento de la nacionalidad (Siete ensayos 303 [EI énfasis es mío]).

Con "Nuestros independientes" Mariátegui expone algunos ejemplos representativos de la nueva conciencia estética del Perú, es decir, aquella que busca posicionar la experiencia del hombre como principio estético. En estos encuentra el pensador peruano el germen de las literaturas nacionales, pues en su diversidad e individualidad (rasgos que Mariátegui persigue en su búsqueda crítica) albergan la suscitación y la anticipación de lo que vendrá a nivel de elaboración e interpretación artística de la condición humana.

Todos ellos son considerados en el mapa mariateguiano por ser "valores signos" o "funciones signos", lo que significa que aglutinan en su obra artística una función expresiva que marca una tendencia no explotada antes. Dicha función expresiva implica un riesgo estético que supera los eventos de producción y recepción de la obra. Las obras consideradas como "valores signos" u ostentadoras de estos sirven a Mariátegui como criterio para "jardinar" el "fárrago" de la literatura peruana. Todo pensador alberga en su posición crítica una idea de literatura; para Mariátegui, la literatura ha de proponer verdaderas apuestas estéticas por innovación, exploración y crítica respecto de la expresión de la experiencia humana. Esta es la razón por la cual el pensador considera que es en el modernismo y en la vanguardia en donde se realizan tales exploraciones críticas.

Al margen de los movimientos, de las tendencias, de los cenáculos y hasta de las propias generaciones no han faltado en el proceso de nuestra literatura casos más o menos independientes y solitarios de vocación literaria. Pero en el proceso de la literatura se borra lentamente el recuerdo del escritor y del artista que no dejan descendencia. El escritor, el artista pueden trabajar fuera de todo grupo, de toda escuela, de todo movimiento. Mas su obra entonces no puede salvarlo del olvido si no es en sí misma un mensaje a la posteridad. Por eso no sobrevive sino el precursor, el anticipador, el suscitador. Por esto las individualidades me interesan, sobre todo por su influencia. Las individualidades, en mi estudio, no tienen su más esencial valor en sí mismas, sino en su función de signos (ibid. 262 [El énfasis es mío]).

Mariátegui no usa la noción de canon ni se propone como objetivo "canonizar" determinada tendencia estética de algún autor u obra. Su idea, más humilde y franca, es la de dejar en evidencia la necesidad de otros tipos de lectura que no se remitan única y exclusivamente a la crítica literaria -"entendida como técnica" (ibid. 318)-, sino que incluyan en su acercamiento nociones más abarcadoras. 
En la misma línea de lectura crítica e interpretativa de los procesos de historia literaria, Reyes en uno de los textos incluidos en Apuntes para la teoría literaria, "Orígenes de la obra literaria", realiza un ejercicio que, aunque no declara aquella "voluntad de desmonte", sí se encuentra enmarcado en esa adopción del pensamiento histórico que venimos tratando. Si bien son apenas "apuntes", es decir, comentarios inacabados que el propio autor no quiso publicar en vida, nos muestran el trayecto hacia donde avanzaban las ideas literarias del pensador mexicano. El texto "Orígenes de la obra literaria" podría ser catalogado como el esquema de un ensayo de mayor desarrollo que no alcanzó a concretarse. Lo que posiblemente perseguía Reyes era elaborar una historia de lo literario desde su más remota raíz en lo ceremonial hasta lo que él denominó "experiencia pura, desinteresada" (El deslinde 481), o sea, la intención estética en sentido estricto. En este tránsito se encuentra considerado tanto el papel colectivo de la "agencia sustantiva", como el papel individual expresivo. Cuando se habla de una literatura propiamente dicha, es decir, de literatura como "fin en sí misma", apuntaba Reyes, es posible hallarla en cualquiera de los "tres estados" desde su "noción evolutiva": independiente y/o autóctona, cosmopolita o en estado de cultura, y colonial. Esta nomenclatura, muy cercana a la usada por Mariátegui, pretende determinar el grado de autonomía expresiva que cierta comunidad poseedora de una literatura (entendida como tal) alberga en sus manifestaciones estéticas.

Literatura independiente $\mathrm{y} / \mathrm{o}$
autóctona

Literatura cosmopolita

Literatura colonial
Estado de aislamiento y de identificación máxima de un pueblo con su territorio

Fase estética pura y contacto entre literaturas

Estado transitorio, ya sea de literatura colonizada o imperial

Nótese que Reyes no considera perjudicial para la expresión autónoma de los pueblos el estado colonial, en contraste con la toma de posición de Mariátegui, quien señala como obstáculos para la definición de una literatura nacional la mentalidad y actitud colonial, tanto de los colonizadores como de los pueblos colonizados. Para Reyes estos tres estados son transitorios y se encuentran en constante cambio en la medida en que los pueblos dialogan, se comunican y/o permanecen en un estado de autocontemplación siempre temporal.

Establezco algunas diferencias: para Reyes, lo cosmopolita alberga la búsqueda estética pura, el contacto dialógico entre literaturas y culturas; esta noción no se encuentra tan distante de la idea de Mariátegui. En las ideas del pensador peruano lo cosmopolita adquiere un carácter de "oportunidad" para asimilar (aprender, reformular) y enriquecer las producciones propias. En su calidad de etapa de aprendizaje, lo cosmopolita posee una carga positiva de evidente valoración del contacto voluntario, que se diferencia significativamente de la imposición colonial. En Reyes, lo colonial, en un sentido no meramente político, actúa como oportunidad de intercambio cultural, "es puente entre los otros dos estados pues suele partir de lo autóctono" (ibid. 485). Este intercambio puede derivar en un avance o retroceso de uno u 
otro lado del contacto colonizador-colonizado; lo colonial nunca es estático ni permanente.

La noción que más difiere entre la perspectiva de Reyes y la de Mariátegui es la idea de literatura independiente o autóctona en contraste con la idea de literatura nacional. Reyes explica que la etapa independiente o autóctona es la de menor contacto con otras producciones de otros pueblos, pues enfatiza en lo relacionado con la autopercepción de un pueblo y su territorio, lo que le atañe exclusivamente a él pero que no es necesariamente primitivo. Lo nacional en Mariátegui es la expresión auténtica de los pueblos que han pasado ya por la emancipación de la colonia y que han hecho -y continúan haciendo- de la oportunidad cosmopolita el recurso para conocerse a sí mismos. En Mariátegui lo nacional es una meta positiva después de un largo proceso; en Reyes lo independiente/autóctono es solo una etapa de afirmación (transitoria).

Vale la pena señalar que los apuntes de Reyes no alcanzan a desarrollar una posición estético-política, como sí sucede en el ensayo de Mariátegui. El propósito de Reyes, en apariencia, más elemental, es el de registrar ese movimiento histórico-genético de la literatura como "cosa en sí". El pensamiento histórico que revela la obra de Reyes difiere del de Mariátegui, por su distancia con la limitación que impuso a este último el marxismo-leninismo. Mientras que Reyes ve en los procesos evolutivos instancias dialógicas y creativas, Mariátegui limita su observación a la lucha de poderes. De todas maneras, se puede extractar la apuesta de cada uno de los pensadores por un tipo de literatura a través de su pensamiento histórico: Mariátegui presenta una idea de literatura nacional en la que la expresión de los pueblos, la expresión humana y viva de los procesos históricos es el centro mediante el trabajo estético que supera la innovación y el acontecimiento; Reyes, por su parte, observa en el movimiento de contacto entre literaturas y culturas diversas la posibilidad de existencia de una literatura autónoma, en la medida en que esta contribuye con la identificación de un pueblo, pero también es capaz de dialogar constructivamente con otras manifestaciones estéticas. Expresión y autonomía son los dos proyectos a los que apuestan Mariátegui y Reyes, respectivamente en su noción de literatura; la expresión supera la idea romántica de "expresión del pueblo" por el carácter crítico y evaluador de los saldos socio-históricos que realiza; y la noción de autonomía, que no se limita al significado político, responde más a la necesidad humana de experimentar un grado de conciencia que contribuye al posicionamiento de las producciones culturales ante la realidad como respuestas crítico-dialógicas.

El giro que da el pensamiento histórico hispanoamericano hacia la historiografía literaria moderna propiamente dicha se puede observar en el circuito problemático que se establece entre Seis ensayos en busca de nuestra expresión [1928], Siete ensayos de interpretación de la realidad peruana [1928] y Las corrientes literarias en la América hispánica [1946], el cual nos permite examinar en detalle lo que significó la entrada y adopción del pensamiento histórico moderno y su contribución al establecimiento del discurso especializado en estudios literarios en Hispanoamérica. Estas tres obras -que no cuentan con precedentes en lengua española- problematizan la forma de asumir la literatura - de leerla y ponerla en circulación-, y crean a su vez mecanismos para establecer un corpus literario hispanoamericano. 
Tanto Henríquez Ureña como Mariátegui evitan enfrascarse en discusiones formales y exclusivamente estilísticas como la de los géneros y formas literarias; eso no significa que no arrojen juicios de valor ante tal o cual logro estético. Ellos sostienen una visión transversal de las búsquedas expresivas sin caer de manera irremediable en la cuestión formal, pues analizan indistintamente textos ensayísticos, poéticos, narrativos, crónicas, cartas, discursos y los incluyen en el corpus o materia expresiva que desean articular dentro de los movimientos generales de la cultura o, para mejor decir, de la toma de conciencia histórica y estética que se proponen explicar.

Lo que más resalta en estos tres trabajos es el deseo de sus autores de abarcar en su amplitud y diversidad a la literatura, y desde una idea de crítica también diversa y amplia, se dirigen a su objeto siempre con el objetivo de encontrarse en un primer estadio del gran proyecto que se proponen adelantar. Implícitamente los pensadores convocan a los lectores a continuar su tarea, a profundizarla y a rebatirla, pues ellos mismos desde sus ejercicios se han propuesto "desmontar" lo existente para hacer de la crítica una expresión viva.

Mariátegui había leído al crítico maduro que ya era Henríquez Ureña para el año 28; desde allí advierte que los conjuntos literarios llamados "nacionales" necesitan ser comprendidos desde su complejidad y profundidad. Henríquez Ureña, por su parte, elabora y profundiza, a partir de su trabajo docente, un extenso recorrido por los nombres más representativos del panorama de las literaturas hispanoamericanas. Los criterios utilizados por el dominicano en su selección y valoración cambian la forma de hacer historia literaria, pues sus referentes ya no son ni el escritor visto como un genio (romántico) ni la historia comprendida a partir de los hechos, sino que su procedimiento para escribir la historia literaria hispanoamericana surge a partir del oficio de escritor -su papel social y su proceso de profesionalización-, y la construcción de la historia a partir de los discursos que la forman.

Observemos estos dos criterios más de cerca. La figura del escritor que se consolida a partir de criterios históricos y sociológicos acompaña también la idea de literatura; al cambiar la función del escritor, consecuentemente cambia la noción de literatura, por lo que el pensador dominicano opta por rastrear esos cambios socio-históricos del oficio del escritor en la América hispana, haciendo de estos señales evidenciables en la producción literaria de "esfuerzo consciente de búsqueda de expresión propia" (Las corrientes 10).

Recordemos que el pensamiento dialéctico presente en la obra del dominicano anuncia desde sus inicios un proyecto que aspira a explicar los movimientos de la cultura en su totalidad, aquello que él optó por llamar la "síntesis cultural", en su ensayo "Utopía de América". Dicha "síntesis" se logra mediante la adecuada conjunción de lo que Benedetto Croce en su Teoría e historia de la historiografía señaló como "documento y crítica, vida y pensamiento" (20), es decir, la reflexión que da vida al documento y, por lo tanto, es capaz de ser verdadera historia (historia moderna), porque privilegia el valor de la vida espiritual de los pueblos (ejercicio de la crítica) antes que la obsesión pueril por el dato estático y concluyente. Con la historiografía de Henríquez Ureña asistimos a la consolidación de la idea de proceso como 
objeto de estudio. El dominicano ensaya en sus dos obras fundamentales, Las corrientes literarias en la América hispánica y La historia de la cultura en la América hispánica, la puesta en forma de una historia moderna de la literatura que se constituye en historiografía porque además de realizar la "historia de una expresión", la interpreta dentro de su propio movimiento sin dar por concluido el proceso, y junto con todo esto reflexiona sobre su idea de la historia, por lo que, al volver sobre el pensamiento histórico hace de este una filosofía de su propio movimiento. En este sentido, los dos criterios que consideró el autor para la elaboración de Las corrientes... son los medios para lograr su fin, en otras palabras, Las corrientes... no constituyen solamente la historia del papel social del escritor en la América hispánica ni tampoco la periodización de las manifestaciones literarias desde el Descubrimiento hasta la vanguardia, sino que su propósito es el de captar la representación del movimiento, de la vida y la transformación de lo que llamamos literatura.

El primer ejemplo de Las corrientes... se centra en Cristóbal Colón, quien antes que ser un escritor sociológicamente entendido es un "intérprete en palabras" de la realidad americana para la mentalidad europea, es él quien construye las percepciones que habitan el imaginario europeo de la América exuberante y de sus habitantes como dóciles creaturas. La "estética" que fundan los navegantes y cronistas basados en la sorpresa de un nuevo entorno, señala Henríquez Ureña, los convierte en los primeros individuos que ven en la letra la herramienta para influir en la percepción de la realidad.

Toda esta literatura desde Colón hasta Palafox, pertenece a la América hispánica mucho más que a España y a Portugal. Es la obra de hombres cuya nueva vida, como dice Ortega, ha hecho de ellos hombres nuevos. Algunas de sus páginas revelaron el nuevo mundo a la imaginación de Europa que tomó de ellos solo unos cuantos tópicos llamativos. Pero en la prodigiosa cantidad de escritos salidos de las plumas de los primeros cronistas y poetas estaba el verdadero Descubrimiento del Nuevo Mundo por ojos europeos. Solo en América pudo entenderse su visión directa que para ellos era una toma de posesión imaginativa e intelectual (ibid. 54-55).

A la par con el rastreo de la figura del escritor, Henríquez Ureña ensaya una historia social de la lectura y la cultura en el subcontinente, porque no solamente dedica sus páginas al "productor literario", sino que con sus gestos de anhelo por la totalidad intenta dar cuenta del movimiento general que envuelve al fenómeno literario. Las relaciones que establece el pensador dominicano nos dejan ver que lo que él se proponía era constatar la incidencia de la literatura en la vida social de la América hispánica, la cual no se limita a los círculos intelectuales o a las elites letradas, sino que afecta concretamente las transformaciones estructurales de las sociedades, pues influye en las percepciones de la realidad; es lo que el dominicano ha considerado como "la creación de una sociedad nueva".

Mediante este "recurso de relación", Henríquez Ureña batalla por la comprensión de los saldos culturales generados a partir de la vivencia de procesos tan complejos como el colonial, cuya visión desde la literatura muestra esfuerzos como los del Inca Garcilaso, quien abre las puertas de 
la imaginación europea a la comprensión de culturas como la incaica, que removió el imaginario clásico y cristiano. La búsqueda de Henríquez Ureña concentrada en dar una visión menos sesgada del proceso colonial en las letras hispanoamericanas, responde a la necesidad cada vez más apremiante de interpretar las trayectorias que América siguió para definir su expresión, más allá de los condicionamientos sociopolíticos y económicos de la época.

De la misma forma que Henríquez Ureña advierte las estrechas relaciones entre literatura y visión del mundo en la Colonia, también observa la incidencia de la escritura y de la figura del escritor, en su capacidad de confrontación y polémica, en los movimientos e ideas independentistas. El pensador resalta el papel de la letra impresa en el cambio de mentalidad tanto de los líderes de la emancipación como del pueblo que siguió los ideales y contribuyó a consolidar el establecimiento de las naciones:

La literatura desempeñó un papel ancilar en su actividad política; en realidad, la había anunciado ya en los escritos de hombres como Baquíjano o Espejo. Los periódicos y folletos fueron esenciales en sus campañas. La difusión de las nuevas ideas, y la ilustración y educación del pueblo, en oposición a la cultura restringida y anticuada que había prevalecido en los tiempos coloniales, juntamente con la perfección de la libertad individual por la abolición de todas las formas de esclavitud y servidumbre, se concebían como concomitantes naturales de la libertad nacional (ibid. 102).

De lo citado anteriormente se extrae la idea de que para Henríquez Ureña la literatura y el escritor se desplazan dentro de la vida social, pues estos no poseen un lugar inamovible y fijo, todo lo contrario, la existencia de las dos instancias -la del escritor y la de la literatura-contribuye a la formación de discursos que al mismo tiempo configuran la vida social. Si para el movimiento independentista la literatura fue un apoyo para la comunicación de las ideas, en el siguiente período de "Romanticismo y Anarquía", el tipo de vida política, de agitación y rebeldía, proporciona espacios para la producción literaria de cierto tono político, ya que en palabras de Henríquez Ureña "Nuestros hombres de letras fueron, pues, por regla general también hombres de acción" (ibid. 120). Pero aquella incidencia del discurso político en la producción literaria hispanoamericana de finales del siglo XIX no solo apuntaba a fortalecer la autonomía política de las nuevas naciones, también se asistió a la exigencia de la autonomía literaria e intelectual que complementaba la dirección política que habían tomado las conciencias de la América hispana. De este gesto ineludible Henríquez Ureña desprende el momento fundamental para las letras modernas de la nueva Hispanoamérica, la tan aclamada profesionalización del escritor y todas sus implicaciones para la historia social de la producción letrada en el subcontinente. Veamos de nuevo este famoso párrafo del apartado "Literatura pura (1890-1920)":

Nacida de la paz y de los principios del liberalismo económico, la prosperidad tuvo un efecto bien perceptible en la vida intelectual. Comenzó una división del trabajo. 
Los hombres de profesiones intelectuales trataron ahora de ceñirse a la tarea que habían elegido y abandonaron la política: los abogados, como de costumbre, menos y después que los demás. El timón del Estado pasó a manos de quienes no eran sino políticos; nada se ganó con eso, antes lo contrario. Y como la literatura no era en realidad una profesión, sino una vocación, los hombres de letras se convirtieron en periodistas o en maestros cuando no en ambas cosas (ibid. 165).

Este momento de la "literatura pura" en el que Henríquez Ureña aborda el fenómeno modernista con sus causas y consecuencias socioculturales, abre la puerta a la discusión ético-estética del arte moderno: con la dedicación exclusiva del escritor a las letras, el arte literario moderno hispanoamericano se enfrenta a la definición de su función social: "Nuestra literatura ha seguido, desde entonces, dos caminos: uno en el que se persiguen fines puramente artísticos; otro en el que los fines en perspectiva son sociales" (ibid. 189). En su argumentación, Henríquez Ureña nos muestra que estas tomas de posición no son excluyentes ni se hallan en el plano de la dicotomía; en casos como el de Martí, el arte comprometido socialmente no descarta al arte comprometido estéticamente. El pensador dominicano problematiza estas tomas de posición, en cuanto tienden a la radicalización de una u otra, ya sea descuidando el trabajo estético o la conciencia social. Subyace a esta polémica nuevamente el cuestionamiento de la función del escritor y de su producto literario. Con las crisis sociales que generó la modernización económica, los problemas de la tierra y del indio, la literatura no podía ignorar el impulso por conservar el espacio que había ganado tras siglos de influencia ancilar. Henríquez Ureña señala algunos logros estéticos que conjugan tales preocupaciones sociales, como los de la novela de la tierra. A la vanguardia hispanoamericana el pensador le reconoce su logro estético, pero el comentario que realiza apenas roza el vanguardismo indigenista que concilió las dos preocupaciones que protagonizaron el temprano siglo XX hispanoamericano: la de la definición de un "arte por el arte" o la de un arte socialmente comprometido.

Concluyo provisionalmente que la literatura, entendida como una forma de expresión autónoma, fue asumida por nuestros intelectuales como una instancia para formular un pensamiento propio hispanoamericano que a la vez fuera crítico y propositivo. Henríquez Ureña, Reyes y Mariátegui no se limitan a probar los vacíos de los discursos epistemológicos tradicionales, sino que de acuerdo con las necesidades intelectuales de nuestro espacio, lanzan propuestas que integran la preocupación exclusiva por un objeto particular, el fenómeno literario, con el universo cultural que lo rodea y lo determina.

Estos procedimientos se hicieron posibles gracias a la incorporación del pensamiento histórico, entendido como ejercicio de adquisición de conciencia cultural. El pensamiento histórico, presente en los discursos críticos en materia literaria, evalúa los saldos tanto de los eventos que han significado cambios en la conducta de los pueblos hispanoamericanos como de los constructos simbólicos que procesan dichos cambios en términos de asimilaciones complejas. La literatura es uno de estos constructos y como tal es una entidad viva que permite la especulación teórica en su carácter 
abstracto, el análisis crítico de realidades particulares en su carácter sociocultural, y la consolidación de discursos englobantes que contribuyen al autoconocimiento de los pueblos.

Ser un sujeto moderno significó para nuestros intelectuales la posibilidad de erigir una voz propia, integrada por un pensamiento e ideas elaboradas contando con su experiencia histórica como sujetos hispanoamericanos. Tal experiencia es reinterpretada constantemente a partir de la conciencia de tradición que cada uno de sus discursos alberga y con la cual elaboran sus visiones sobre el pasado, el presente y el futuro. Sus propuestas ostentan la creencia en el futuro expresivo hispanoamericano y en el de los discursos literarios y estéticos en formación, pues plantean que el pensamiento sistemático sobre los fenómenos culturales es un sendero por el que el hombre aprende a conocerse y a comprenderse. Estos no son solo discursos sobre la literatura, sino que son discursos que reflexionan sobre el lugar que ocupa el ser humano en el mundo y en la historia, y la visión que tiene de sí mismo.

La crítica, entendida como ejercicio del espíritu, como manifestación transhistórica de la expresión humana, es la guía de todo el pensamiento literario de nuestros intelectuales. Ellos le otorgan el lugar legítimo de productividad, cambio y movimiento que esta genera y la despojan del sentido negativo que esta poseía como discurso "parásito", sobre todo con relación a las artes: "Planteamos al hombre ante su mundo. Desde que lo percibe, ya no es pasivo: obra sobre él para adquirirlo, para dejarlo entrar en su ser. Y aquí comienza el debate epistemológico" (Reyes, Al yunque 292). La crítica es la facultad humana para discernir e intervenir la realidad bajo una posición de individualidad responsable; en su presencia el pensamiento no puede estancarse, pues esta actúa como impulso de movilidad y crecimiento perpetuo. La crítica literaria es la materialización de la conciencia creadora y receptora, frente a ella la creación es disfrute y este disfrute nunca se agota, la crítica permite el continuo disfrute del objeto estético.

De los trabajos de nuestros tres pensadores se puede extractar, como conclusión provisional, que el estudio de la expresión literaria tiene en ellos por lo menos una condición doble: a) la de mostrar que la literatura es expresión que se basta a sí misma y que puede soportar sobre sus hombros el peso de una disciplina que se ocupe de ella en su carácter estético, social e histórico $y, b$ ) que la literatura constituye una plataforma de conciencia cultural a partir de la cual el ser humano se puede pronunciar como sujeto crítico. La literatura es un eslabón en la cadena de procesos culturales que contribuye a la intelección del mundo y de la realidad, pues esta es siempre una elaboración colectiva permanente.

\section{Obras citadas}

Henríquez Ureña, Pedro. Las corrientes literarias en la América Hispánica [1945]. Ciudad de México: F.C.E., 2001. Obra Crítica [1960]. Ciudad de México: F. C. E., 2001. Utopía de América. Caracas: Biblioteca Ayacucho, 1989.

Picón-Salas, Mariano. De la conquista a la independencia. Ciudad de México: F. C. E., 1994. 
Mariátegui, José Carlos. Siete ensayos e interpretación de la realidad peruana [1928]. Ciudad de México: Ediciones Era, 2002.

Reyes, Alfonso. "La experiencia literaria", "Tres puntos de exegética literaria" Obras completas [1962]. Vol. XIV. Ciudad de México, 1997.

"El deslinde", "Apuntes para la teoría literaria", Obras completas, [1963]. Vol. XV. Ciudad de México, 1997.

"Al yunque", Obras completas [1960]. Vol. XXI. Ciudad de México: F.C.E., 2000.

Croce, Benedetto, Teoría e historia de la historiografía. Buenos Aires: Ediciones Imán, 1953.

Mariaca, Guillermo. El poder de la palabra. La crítica cultural hispanoamericana [1993]. Santiago de Chile: Tajamar Ediciones, 2002.

Promis, José. Testimonios y documentos de la literatura chilena. Santiago de Chile: Editorial Andrés Bello, 1995.

Rincón, Carlos. "Historia de la historiografía y la crítica literarias latinoamericanas: historia de la conciencia histórica", Revista de Crítica Literaria Latinoamericana, año 11, № 24 (20 Semestre 1986): 7-19.

Gutiérrez Girardot, Rafael. Prólogo. Pedro Henríquez Ureña. Utopía de América. Caracas: Biblioteca Ayacucho, 1989. IX-XXXVII.

"Pedro Henríquez Ureña y la historiografía literaria latinoamericana", Pedro Henríquez Ureña, Ensayos. José Luis Abellán y Ana María Barrenechea (comps.). Madrid: ALLCA XX/ Editorial Universitaria, 1998.

Beigel, Fernanda. El itinerario y la brújula: el vanguardismo estético-político de José Carlos Mariátegui. Buenos Aires: Biblos, 2003.

La epopeya de una generación y una revista. Las redes editoriales de José Carlos Mariátegui. Buenos Aires: Editorial Biblos, 2006.

Dessau, Adalbert. "Literatura y sociedad en las obras de José Carlos Mariátegui", Mariátegui, tres estudios. Lima: Empresa Editora Amauta, 1971.

Melis, Antonio. "Tradición y modernidad en el pensamiento de Mariátegui". Anuario Mariateguiano No 6, vol. VI (1994): 73-80.

"La fundación de la historia literaria hispanoamericana: Pedro Henríquez Ureña y José Carlos Mariátegui". Anuario Mariateguiano No 9, vol. IX (1997): 35-40.

Sarlo, Beatriz. "Pedro Henríquez Ureña, lectura de una problemática". Pedro Henríquez Ureña, Ensayos. José Luis Abellán y Ana María Barrenechea (comps.). Madrid: ALLCA XX/ Editorial Universitaria, 1998: 822-825. 